\title{
Padrão de integração de pAN7-1 em mutantes de Magnaporthe grisea com patogenicidade alterada em arroz
}

\author{
Carlos Eduardo Marchi ${ }^{1}$, Sérgio Hermínio Brommonschenkel ${ }^{2}$, Marisa Vieira de Queiroz ${ }^{3}$, Mírian de Freitas Borges ${ }^{1}$ \\ \& Eduardo Seiti G Mizubuti²
}

${ }^{1}$ Laboratório Nacional Agropecuário (LANAGRO/SP), Base Física de Jundiaí, SP, CEP 13208-051, Jundiaí, SP, ${ }^{2}$ Departamento de Fitopatologia, ${ }^{3}$ Departamento de Microbiologia, Universidade Federal de Viçosa (UFV), CEP 36570-000, Viçosa, MG. Parte da Tese do primeiro autor apresentada a UFV. (2003).

Autor para corres pondência: Carlos Eduardo Marchi. (carlos.marchi@agricultura.gov.br)

Data de chegada: 25/08/2008. Aceito para publicação em: 30/10/2009.

\section{RESUMO}

Marchi, C.E.; Brommonschenkel, S.H.; Queiroz, M.V. de; Borges, M. de F.; Mizubuti, E.S.G. Padrão de integração de pAN7-1 em mutantes de Magnaporthe grisea com patogenicid ade alterada em arroz. Summ a Phytopathologica, v.36, n.1, p.21-24, 2010.

Ensaios foram conduzidos para verificar a presença, o número de cópias e de sítios de integração de pAN7-1 no genoma de mutantes de M. grisea I-22 com patogenicidade alterada em arroz. Foram analisados T41, T93, T251 (gerados por mutagênese REMI) e T108 (oriundo de mutagênese convencional), os quais exibiram diferentes fenótipos mutantes. O DNA total desses mutantes foi submetido à reação em cadeia de polimerase $(\mathrm{PCR})$ e às análises de hibridização com o vetor (Southern blot). A presença de pAN7-1 no genoma de todos os mutantes foi confirmada por PCR. Segundo as análises de Southern blot, T41 exibiu duas integrações do vetor, ambas na forma de cópia única. No genoma de T93 também foram detectados dois sítios de inserção de pAN7-1, um dos quais envolvendo múltiplas cópias do vetor. Os resultados indicaram a presença de apenas uma cópia do vetor em um único sítio nos genomas de T108 e T251. O padrão de integração em T251 foi o único a sugerir a ocorrência de evento REMI. As diferenças quanto ao tamanho dos fragmentos com homologia a pAN7-1 refletiram a possível aleatoriedade dos eventos de integração no genoma de $M$. grisea. Os resultados evidenciaram o potencial de REMI para a mutagênese insercional de M. grisea, quando conduzida com pAN7-1 e HindIII

Palavras-chave adicionais: Brusone, genes de patogenicidade, mutagênese insercional, Oryza sativa, Pyricularia grisea, REMI.

\section{ABSTRACT}

Marchi, C.E.; Brommonschenkel, S.H.; Queiroz, M.V. de; Borges, M. de F.; Mizubuti, E.S.G. pAN7-1 integration pattern in mutants of Magnaporthe grisea impaired in pathogenicity to rice. Sum ma Phytopathologica, v.36, n.1, p.21-24, 2010.

Experiments were conducted to investigate the presence, number of copies and integration site of pAN7-1 in the genome of mutants of Magnaporthe grisea impaired in pathogenicity to rice. The mutants T41, T93, T251 (obtained by REMI) and T108 (obtained by conventional mutagenesis) exhibiting different alterations in pathogenicity were analyzed. Polymerase chain reaction (PCR) and Southern blot analyses were conducted with total DNA of mutants. The presence of pAN7-1 in genome of mutants was confirmed by PCR. Based in Southern blot analyses, two single-copy integration of vector were detected in T41. Two insertion sites of pAN7-1 were detected in the genome of T93, including an event of tandem integration. The results indicated the presence of a single-copy vector in single location in T108 and T251 genomes. Only T251 showed integration pattern of pAN7-1 suggesting the occurrence of REMI event. The difference in size of hybridizing band indicated the possible randomness of integration events in $M$. grisea genome. The potential of REMI to mutagenesis in M. grisea, using pAN7-1 and HindIII, was evidenced.

Keywords: Rice blast, pathogenicity genes, ins ertional mutagenesis, Oryza sativa, Pyricularia grisea, REMI.

Programas de mutagênese insercional mediada por transformação têm contribuído grandemente para a prospecção de genes envolvidos na patogenicidade de Magnaporthe grisea (T.T. Hebert) M.E. Barr, o patógeno mais destrutivo da cultura do arroz (Oryza sativa L.). Nos últimos anos, a técnica REMI, Restriction Enzyme-Mediated Integration (16) tem se destacado por potencializar a geração de mutações no genoma do ascomiceto $(1,5,11,17,18,20)$. REMI envolve a transformação do organismo com o DNA transformante linear na presença de enzima de restrição, geralmente a mesma utilizada para a linearização do vetor (19). O resultado é a formação de extremidades coesivas compatíveis entre o vetor e o DNA genômico, o que tem aumentado a eficiência de transformação e predominância de integrações simples.

Recentemente, REMI foi adequada para o emprego do vetor pAN7-1 e a enzima HindIII em M. grisea (11). Tal vetor, apesar de amplamente utilizado em outros sistemas, não tem sido explorado para a mutagênese REMI em $M$. grisea. A análise parcial da coleção dos transformantes resultante, gerada principalmente por REMI, permitiu a identificação de cinco mutantes para a patogenicidade (12). Dois desses mutantes, T93 e T108, causaram poucas lesões em folhas, enquanto o mutante T251 não foi patogênico. O mutante T108, obtido por meio de transformação convencional, adicionalmente, exibiu menor 
capacidade de desenvolvimento in vitro. Já os mutantes T41 e T72 apresentaram agressividade reduzida e maior período de incubação, respectivamente. Atraso considerável na germinação de conídios e formação de apressórios também foi verific ado em T72 (12).

O objetivo deste trabalho foi verificar a presença do vetor de transformação no genoma de quatro dos mutantes de $M$. grisea supracitados (T41, T93, T108 e T251), analisando o número de cópias e sítios de integração de pAN7-1.

\section{MATERIALE MÉTODOS}

Mutantes de Magnaporthe grisea I-22 e condições de cultivo

Foram analisados os mutantes para a patogenicidade alterad a em arroz gerados por Marchi et al. (12), especificamente T41, T93, T108 e T251. Enquanto os mutantes T93 e T251 foram obtidos por meio de integração de pAN7-1 mediada por $50 \mathrm{U}$ e $30 \mathrm{U}$ de HindIII, respectivamente, T108 foi gerado por transformação convencional (integração não mediada por enzima de restrição), utilizando o vetor linearizado. Por sua vez, a mutação insercional em T41 foi gerada sem a adição de HindIII à reação de transformação, porém, foi favorecida pela atividade residual da enzima utilizada para a linearização do vetor $(11,12)$. O isolado selvagem I-22, patogênico a plantas de arroz, cedido pelo Laboratório de Fitopatologia Molecular da Universidade Federal do Rio Grande do Sul, Porto Alegre, RS, foi utilizado como controle.

Rotineiramente, o fungo foi cultivado em meio de farinha de arrozágar (FAA- $20 \mathrm{~g}$ de farinha de arroz com casca, $5 \mathrm{~g}$ de sacarose, $15 \mathrm{~g}$ de ágar, $1 \mathrm{~L}$ de água destilada) por cinco a sete dias, em $\mathrm{BOD}$ a $28^{\circ} \mathrm{C}$ no escuro. No caso dos mutantes, foram adicionados $100 \mathrm{mg}$ de higromicina/mL no meio FAA. Para a preservação do fungo em longo prazo, pedaços $\left(4 \mathrm{~cm}^{2}\right)$ de papel manteiga colonizados pelo mic élio foram mantidos $\mathrm{a}-80^{\circ} \mathrm{C}(21)$.

\section{Extração de DNA}

O fungo foicultivado em meio completo $(0,5 \%$ de sacarose, $0,3 \%$ de extrato de levedura, $0,3 \%$ de caseína hidrolisada), sob agitação (130 - $150 \mathrm{rpm}$ ) durante 10 - 14 dias a $28^{\circ} \mathrm{C}$, no escuro. As extrações de DNA foram realizadas conforme Scheuermann (15). Brevemente, o micélio, uma vez seco e macerado em nitrogênio líquido, foi transferido para tubo de microcentrífuga e misturado com $750 \mathrm{~mL}$ de tampão de extração (CTAB a $55 \mathrm{mM}$, Tris a $100 \mathrm{mM}, \mathrm{pH}$ 8,0, EDTA a $10 \mathrm{mM}$, $\mathrm{NaCl}$ a $0,7 \mathrm{M}$ ) e $15 \mathrm{~mL}$ de mercaptoetanol. Após inc ubação a $65^{\circ} \mathrm{C}$ por 30 minutos, foram acrescentados $500 \mathrm{~mL}$ de fenol-clorofórmio-álcool isoamílico (25:24:1) e a mistura foi centrifugada por cinco minutos a $14.000 \mathrm{rpm}$. A fase aquosa superior foi transferida para outro microtubo, adicionados $500 \mathrm{~mL}$ de clorofórmio-álcoolisoamílico (24:1), e a mistura foi centrifugada novamente. A fase líquida foi transferida para microtubo contendo $750 \mathrm{~mL}$ de isopropanol $\left(-20^{\circ} \mathrm{C}\right)$, incubada em gelo por 10 minutos e centrifugada. Por fim, o precipitado foi lavado duas vezes com $1 \mathrm{~mL}$ de etanol $70 \%\left(-20^{\circ} \mathrm{C}\right)$, seco e ressuspendido em $50 \mathrm{~mL}$ de tampão TE (Tris a $10 \mathrm{mM}, \mathrm{pH} 8,0$, EDTA a $1 \mathrm{mM}$ ). A concentração do DNA foi estimada por comparação com padrões de DNA. As amostras de DNA foram armazenadas a $20^{\circ} \mathrm{C}$.

\section{Polymerase Chain Reaction (PCR)}

Para verificar a presença de pAN7-1 no genoma dos mutantes de M. grisea I-22 que apresentaram patogenicidade alterada ao arroz, PCR foi conduzida com os oligonucleotídeos hph1 e hph2, que anelam especificamente na região estrutural do gene $H P H$, utilizado como marcador de seleção. Após a extração, o DNA total foi submetido à amplificação utilizando os oligonucleotídeos específicos hph1 (CAGCGAGAGCCTGACCTATTGC) e hph2 (GCCATCGGTCCAGACGGCCGCGC). O programa de amplificação consistiu de um ciclo de desnaturação de dois minutos a $95^{\circ} \mathrm{C}$, seguido por 30 ciclos com um minuto de desnaturação $\left(92^{\circ} \mathrm{C}\right), 60$ segundos para o anelamento dos oligonucleotídeos a $60^{\circ} \mathrm{C}$, e 90 segundos de polimerização a $72^{\circ} \mathrm{C}$. Os amplicons foram visualizados em gel de agarose a $1,4 \%$.

\section{Análise de Southern blot}

Aproximadamente 2,5 mg de DNA do indivíduo selvagem e dos mutantes selecionados foram digeridos com a enzima HindIII, ClaIou $E c o$ RV. Os fragmentos de digestão foram fracionados em um gel de agarose a $0,8 \%$ e transferidos para membrana de náilon (Stratagene ${ }^{\circledR}$ ou Hybond-N) de acordo com Sambrook et al. (13). A marcação da sonda (pAN7-1), hibridização e detecção do sinal foram realizadas com o Gene Images Random-Prime Labelling Module Kit e CPD-Star Detection Module (Amersham), segundo as instruções dos fabricantes. Para a marcação da sonda com a- ${ }^{32} \mathrm{P}-\mathrm{CTP}$ utilizou-se o sistema Rediprime II (Amersham), conforme instruções do fabricante.

\section{RESULTADOS E DISCUSSÃO}

A integração de pAN7-1 no genoma dos mutantes para a patogenicidade alterada em arroz (T41, T93, T108 e T251) foi confirmad a pela reação de PCR (Figura 1). As reações positivas foram caracterizadas pela amplificação de fragmentos de DNA com 690 pb, correspondentes à presença do gene de seleção $H P H$.

A confirmação da presença de pAN7-1 no genoma dos mutantes, contudo, não garante que as alterações para a patogenicidade em arroz, identificadas nos mesmos por Marchi et al. (12), foram resultantes do evento de integração do vetor. Com respeito a REMI, embora eficiente no estudo da patogenicidade fúngica, tem sido significativa a taxa de mutações não marcadas fisicamente (deleções e rearranjamento de DNA genômico), as quais podem ser geradas espontaneamente ou pelo reparo

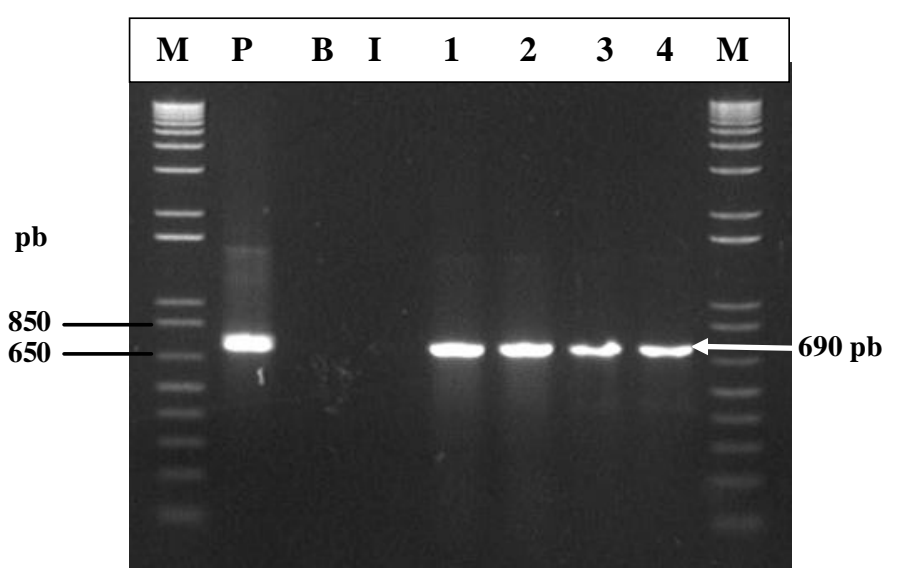

Figura 1. Perfil eletroforético dos amplicons dos mutantes de Magnaporthe grisea I-22, utilizando os oligonucleotídeos hph1 e hph2. M: marcador de tamanho $1 \mathrm{~Kb}$ Plus (Invitrogen $囚) ; \mathbf{P}:$ pAN7-1; B: reação controle, contendo todos os reagentes, exceto o DNA; I: $M$. grisea I-22; 1: T41; 2: T93; 3: T108 e 4: T251. Os fragmentos de 850 e 650 pares de base (pb) do marcador estão indicados na margem esquerda. A seta indica os amplicons de $690 \mathrm{pb}$ esperados. 
do DNA induzido pela técnica (10). Em M. grisea, Sweigard et al. (20) obtiveram cerca de 1/3 de mutantes REMI não marcados pela presença do vetor de transformação, em alguns casos envolvendo grandes deleções de DNA.

A correlação entre o fenótipo mutante e a inserção do vetor pode ser verificada por meio da clonagem da sequência interrompida pelo DNA transformante, a qual é posteriormente utilizada para restaurar o fenótipo selvagem. Para isso, inicialmente foram conduzidas análises de Southern blot para determinar o padrão de integração de pAN7-1 no genoma dos mutantes T41, T93, T108 e T251, as quais subsidiarão os trabalhos de clonagem.

O uso de ClaI ou EcoRV, enzimas que não possuem sítios de restrição no vetor, permitiu detectar o número de sítios de integração no DNA genômico. Pela clivagem do DNA não ocorrer na sequência de pAN7-1, foram esperados fragmentos com homologia ao vetor superiores a 6,75 $\mathrm{Kb}$ (tamanho de pAN7-1). Para cada mutante, as hibridizações realizadas com DNA-ClaI e DNA-EcoRV apresentaram similaridades entre os padrões de integração do vetor (Figura 2).

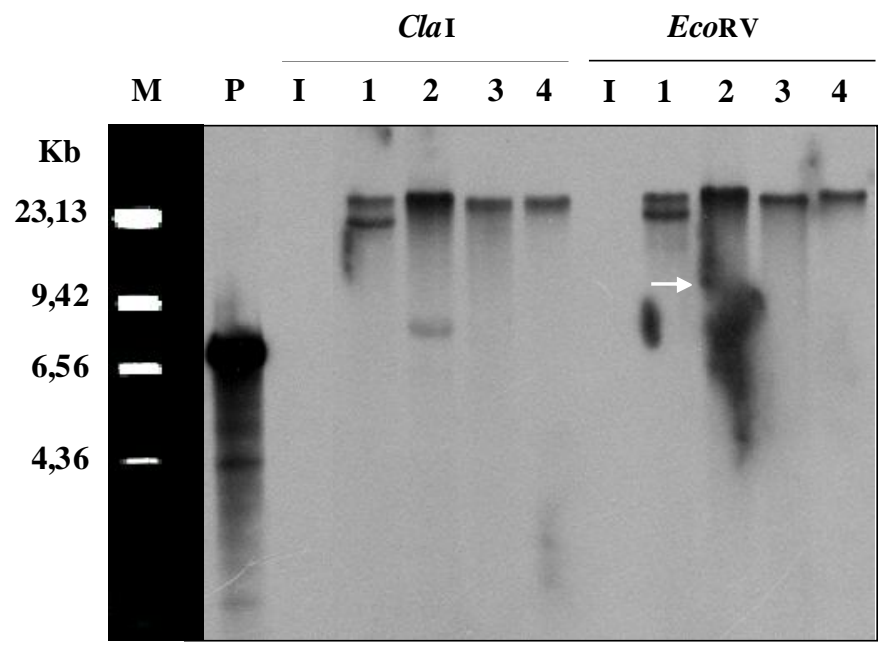

Figura 2. Padrão de integração de pAN7-1 em mutantes de Magnaporthe grisea I-22. O DNA total foi clivado com ClaI ou EcoRV e pAN7-1 marcado com dUTP-fluoresceína foi utilizado como sonda. M: $\lambda$ DNA clivado com HindIII. P: pAN7-1 linearizado com HindIII. I: I-22. Linhas 1, 2, 3 e 4 correspondem a T41, T93, T108 e T251, respectivamente. O tamanho $(\mathrm{Kb})$ dos fragmentos $\lambda$ DNA-HindIII estão indicados na margem esquerda. A seta indica um dos fragmentos com homologia a pAN7-1 do mutante T93.

A clivagem do DNA dos mutantes com HindIII, a enzima usada em REMI, permitiu determinar a ocorrência de integrações múltiplas cópias (in tandem), bem como dos eventos REMI propriamente ditos. Tais eventos foram detectados pela presença de fragmentos com homologia a pAN7-1 com tamanho igual a $6,75 \mathrm{~Kb}$, indicando a restauração dos sítios de restrição. De acordo com esta análise, constataram-se diferenças no padrão de integração do vetor no genoma dos mutantes T41, T93, T108 e T251 (Figura 3).

Quando o DNA de T41 foi clivado com ClaI ou EcoRV, foi possível verificar que pAN7-1 integrou-se em dois sítios no genoma do fungo (Figura 2, linha 1). A análise conduzida com HindIII revelou dois fragmentos com homologia a pAN7-1, com tamanhos superiores a $6,75 \mathrm{~Kb}$ (Figura 3, linha 1). As análises de Southern blot indicaram tratar-se de duas integrações do tipo única cópia, as quais não apresentaram a restauração de todos os sítios de restrição HindIII pelo sistema de reparo de DNA da célula.

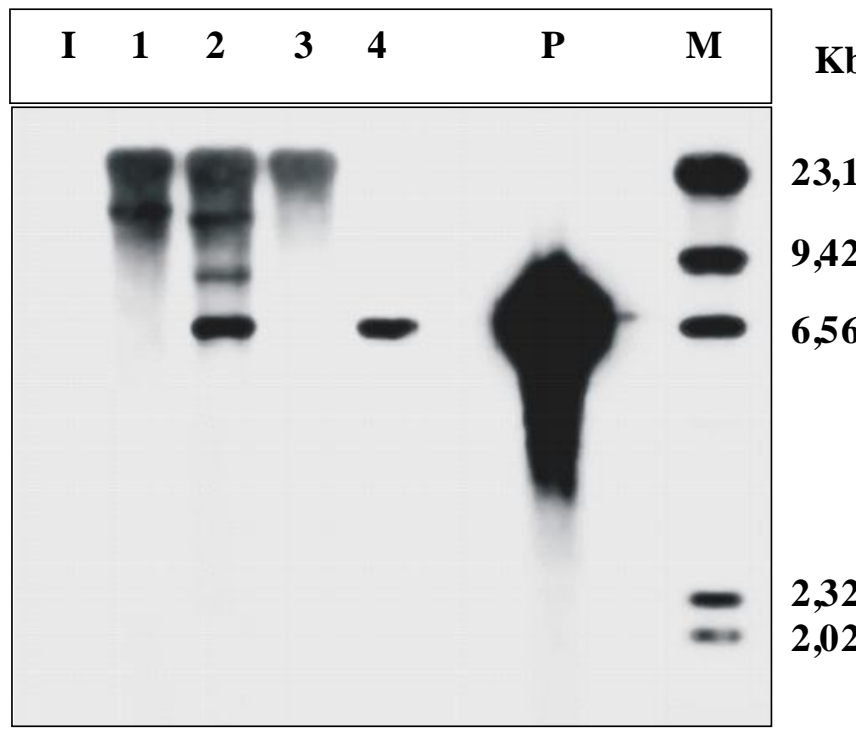

Figura 3. Padrão de integração de pAN7-1 em mutantes de Magnaporthe grisea I-22. O DNA total foi clivado com HindIII e pAN7-1 marcado com a- ${ }^{32}$ P-CTP foi utilizado como sonda. M: $\lambda$ DNA clivado com HindIII. P: pAN7-1 linearizado com HindIII. I: I-22. Linhas 1, 2, 3 e 4 correspondem a T41, T93, T108 e T251, respectivamente. O tamanho (Kb) dos fragmentos $\lambda$ DNA-HindIII estão indicados na margem esquerda.

O T93 foi o mutante que apresentou padrão de integração de pAN7-1 mais complexo. Também foram detectados dois sítios de inserção do vetor no DNA genômico, identificados pela presença de dois fragmentos com homologia a pAN7-1 (Figura 2, linha 2). Quando a hibridização foi conduzida com o DNA de T93 clivado com HindIII, foram visualizados quatro fragmentos, um dos quais com $6,75 \mathrm{~Kb}$ (Figura 3, linha 2). Os resultados sugeriram que, nesse mutante, uma das integrações de pAN7-1 no genoma foido tipo in tandem (fragmento maior, com sinal mais intenso) (Figura 2, linha 2). Em alguns sistemas, REMI tem induzido frequência considerável de integrações do vetor in tandem. Shi et al. (18), por exemplo, observaram tais eventos em 5\% dos transformantes REMI de M. grisea. As inserções do tipo in tandem podem ser geradas pela formação de concatâmeros do vetor priori à transformação ou por repetidos ciclos de recombinação homóloga após inserção do DNA transformante no genoma fúngico (3). Para Penicillium paxilli Bainier, a defosforilação de pAN7-1, para prevenir a formação de concatâmeros, não reduziu a frequência de integrações in tandem, sugerindo que, para algumas espécies fúngicas, predominam os eventos de recombinação homóloga entre cópias do vetor (7).

As análises de Southern blot conduzidas com ClaI ou EcoRV revelaram a presença de apenas um fragmento comhomologia a pAN71 no genoma de T108, indicando um único sítio de integração do vetor (Figura 2, linha 3). A hibridização realizada com o DNA-HindIII desse mutante também resultou na presença de apenas um fragmento com homologia ao vetor (Figura 3, linha 3), de tamanho superior a 6,75 Kb. Os resultados permitiram inferir que, nesse mutante, apenas uma cópia de pAN7-1 integrou-se em um único sítio no DNA fúngico, muito provavelmente, fora de um sítio de restrição HindIII, visto que T108 originou-se de transformação convencional.

O mutante T251 também apresentou apenas um único fragmento com homologia ao vetor, independente da análise de Southern blot (Figuras 2 e 3, linha 4), ou seja, apresentou apenas uma cópia de pAN7-1 integrada em um único sítio no DNA fúngico. Contudo, o 
fragmento com homologia a pAN7-1 detectado com o DNA-HindIII apresentou tamanho igual ao de pAN7-1 (Figura 3, linha 4). Esse padrão de integração foi o único a sugerir a ocorrência de restauração dos sítios de restrição de HindIII, ou seja, evento REMI. Indivíduos com o padrão de integração semelhante à T251 foram previamente considerados ideais para a clonagem de genes via recuperação do vetor $(9,14,16)$.

REMI é preconizada como uma técnica que favorece os eventos de integração do vetor em únic o sítio do genoma, sobretudo na forma de cópia única. Dos três mutantes REMI, apenas T251 apresentou uma simples cópia de pAN7-1 integrada em um único sítio no genoma de I-22 (Figura 2, linhas 1, 2e 4). Contudo, índic es superiores já foram constatados para M. grisea (18). Poroutro lado, as análises de Southern blot conduzidas com os mutantes REMI exibiram diferenças quanto ao tamanho dos fragmentos com homologia a pAN7-1, o que refletiu a possível aleatoriedade dos eventos de integração.

Esforços iniciais para isolar as sequências inativadas, usando o protocolo de Kuspa \& Loomis (8), não foram bem sucedidos. As colônias de Escherichia coli T. Escherich (linhagem DH5-a) continham apenas o vetor pAN7-1 vazio (sem as sequiências genômicas flanqueadoras) ou um plasmídeo de tamanho menor, com deleção do fragmento $E c o$ RI (dados não apresentados). Bölker et al. (2) enfrentaram problemas semelhantes na recuperação do vetor pSMUT do genoma de Ustilago maydis (DC.) Corda. Para este caso, os autores atribuíram a causa do fenômeno à recombinação dentro de fragmentos contendo cópias múltiplas do vetor. Ensaios de rec uperação do vetor deverão ser conduzidos com outras bactérias e outras enzimas. Pelo menos para T251, que apresentou evento REMI, a recuperação da sequência inativada poderá ser efetuada com PCR invertida (4), utilizando oligonucleotídeos que anelam nas extremidades de pAN7-1.

O padrão de integração do vetor nos mutantes REMI, caracterizado pelo baixo número de cópias no genoma e a aleatoriedade dos eventos de inserção, aliado à eficiência de transformação obtida por Marchi et al. (11), indicaram o potencial de REMI para a mutagênese insercional de $M$. grisea quando conduzida com pAN7-1 e HindIII. Programas de mutagênese REMI, conduzidos com as característic as supracitadas, cons tituem ferramenta importante para a prospecção dos genes de $M$. grisea envolvidos na patogenicidade em arroz, cuja compreensão é fundamental para o es tabelecimento de estratégias eficientes de manejo da doença.

\section{REFERÊNCIAS BIBLIOGRÁFICAS}

1. Balhadère, P.V.; Foster, A.J.; Talbot, N.J. Identification of pathogenicity mutants of the rice blast fungus Magnaporthe grisea by insertional mutagenesis. Molecular Plant-Microbe Interactions, St. Paul, v. 12, p. 129-142, 1999.

2. Bölker, M.; Böhnert, H.U.; Braun, K.H.; Görl, J.; Kahmann, R. Tagging pathogenicity genes in Ustilago maydis by restriction enzyme-mediated integration (REMI). Molecular and General Genetics, New York, v. 248, p. 547-552, 1995.

3. Brown, J.S.; Holden, D.W. Insertional mutagenesis of pathogenic fungi. Current Opinion in Microbiology, Amsterdam, v. 1, p. 390-394, 1998.

4. Clergeot, P.H.; Gourgues, M.; Cots, J.; Laurans, F.; Latorse, M.P.; Pépin, R.; Tharreau, D.; Notteghem, J.L.; Lebrun, M.H. PLS1, a gene encoding a tetraspanin-like protein, is required for penetration of rice leaf by the fungal pathogen Magnaporthe grisea. Proceedings of the National Academy of Sciences of the
United States of America, Washington, v. 98, p. 6963-6968, 2001.

5. Fujimoto, D.; Shi, Y.; Christian, D.; Mantanghihan, J.B.; Leung, H. Tagging quantitative loci controlling pathogenicity in $\mathrm{Mag}$ naporthe grisea by insertional mutagenesis. Physiological and Molecular Plant Pathology, Bristol, v. 61, p. 77-88, 2002.

6. Idnurm, A.; Howlett, B.J. Pathogenicity genes of phytopathogenic fungi. Molecular Plant Pathology, Bristol, v. 2, 241-255, 2001 .

7. Itoh, Y.; Scott, B. Effect of de-phosphorylation of linearized pAN7-1 and of addition of restriction enzyme on plasmid integration in Pennicillium paxilli. Current Genetics, G:oteborg, v. 32, v. 147-151, 1997.

8. Kuspa, A.; Loomis, W.F. Tagging developmental genes in Dictyostelium by restriction enzyme-mediated integration of plasmid DNA. Proceedings of the National Academy of Sciences of the United States of America, Washington, v. 89, p. 8803-8807, 1992.

9. Lu, S.; Lyngholm, L.; Yang, G.; Bronson, C.; Yoder, O.C.; Turgeon, B.G. Tagged mutations at the Tox 1 locus of Cochliobolus heterostrophus by restriction enzyme-mediated integration. Proceedings of the National Academy of Sciences of the United States of America, Washington, v. 91, p. 12649-12653, 1994.

10.Marchi, C.E. Mutantes insercionais de Magnaporthe grisea com patogenicidade al terada em arroz. 2003. 136p. (Doutorado em Fitopatologia) - Universidade Federal de Viçosa, Viçosa, 2003.

11.Marchi, C.E.; Brommonschenkel, S.H.; Queiroz, M.V. de; Mizubuti, E.S.G. Integração de pAN7-1 no genoma de Magnaporthe grisea mediada por enzima de restrição. Fitopatologia Brasileira, Lavras, v. 31, p. 254-260, 2006.

12.Marchi, C.E.; Brommonschenkel, S.H.; Queiroz, M.V. de; Borges, M. de F.; Mizubuti, E.S.G. Mutantes insercionais de Magnaporthe grisea com patogenicidade alterada em arroz. Tropical Plant Pathology, Lavras, v. 33, p. 55-62, 2008.

13.Sambrook, J.; Fritsch, E. F.; Maniats, T. Molecular cloning: a laboratory manual. $2^{\text {nd }}$ ed. New York. Cold Spring Harbor laboratory Press. 1989. 545 p.

14.Sánchez, O.; Navarro, R.E.; Aguirre, J. Increased transformation frequency and tagging of developmental genes in Aspergillus nidulans by restriction enzyme-mediated integration (REMI). Molecular and General Genetics, New York, v. 258, p. 8994, 1997.

15.Scheuermann, K.K. Análise da variabilidade de Magnaporthe grisea no estado de Santa Catarina. 2002. 73p. (Mestrado em Fitotecnia). Universidade Federal do Rio Grande do Sul, Porto Alegre, 2002.

16. Schiestl, R.H.; Petes, T.D. Integration of DNA fragments by illegitimate recombination in Saccharomyces cerevisiae. Proceedings of the National Academy of Sciences of the United States of America, Washington, v. 88, p. 7585-7589, 1991.

17.Shi, Z.; Leung, H. Genetic analysis of sporulation in Magnaporthe grisea by chemical and insertional mutagenesis. Molecular Plant-Microbe Interactions, St. Paul, v. 8, p. 949-959, 1995.

18.Shi, Z.; Christian, D.; Leung, H. Enhanced transformation in Magnaporthe grisea by restriction enzyme-mediated integration of plasmid DNA. Phytopathology, St. Paul, v. 85, p. 329-333, 1995.

19.Sweigard, J. A REMI primer for filamentous fungi. International Society for Molecular Plant-Microbe Interactions Reporter, St. Paul, Spring, p. 3-5, 1996.

20.Sweigard, J.A.; Carroll, A.M.; Farrall, L.; Chumley, F.G.; Valent, B. Magnaporthe grisea pathogenicity genes obtained through insertional mutagenesis. Molecular Plant-Microbe Interactions, St. Paul, v. 11. p. 404-412, 1998.

21.Valent, B.; Farrall, L.; Chumley, F.G. Magnaporthe grisea genes for pathogenicity and virulence identified through a series of backcrosses. Genetics, Pittsburgh, v. 127, p. 87-101, 1991. 